\title{
Growing broccoli under salinity: the influence of cultivar and season on glucosinolates
}

\section{content}

\author{
Juan J. Rios ${ }^{1 \oplus}$, Agatha Agudelo²๑, Diego A. Moreno ${ }^{3 \oplus}$, Micaela Carvajal ${ }^{1 *} \oplus$
}

${ }^{1}$ CEBAS-CSIC - Grupo de Aquaporinas - Dpto. de Nutrición Vegetal, Campus Universitario de Espinardo, 25 - E-30100 - Murcia, Spain.

${ }^{2}$ Sakata Seed Iberica, PI. Poeta Vicente Gaos - 46021 Valencia - Spain.

${ }^{3}$ CEBAS-CSIC - Lab. de Fitoquímica y Alimentos Saludables Dpto. de Ciencia y Tecnología de Alimentos, 25 - E-30100

- Murcia, Spain.

*Corresponding author <mcarvaja@cebas.csic.es>

Edited by: Mohammad Valipour

Received February 06, 2019

Accepted May 06, 2019
ABSTRACT: The evaluation of factors that affect glucosinolates (GLS) concentrations in the roots, leaves, and inflorescence of broccoli plants is important in the improvement of the concentration of bioactive compounds and thus in the enhancement of the nutritional properties. In this work, the yield and the concentration of GLS of seven broccoli cultivars (Brassica oleracea var. italica) grown under salinity in field conditions were studied during three different seasons (autumn, winter, and spring). The results show that, generally, salinity did not alter significantly the inflorescence yield during any of the seasons, indicating a high tolerance of the cultivars tested. Yield was reduced only in cultivar Gea in autumn and in cultivar Parthenon in spring. The distribution of the GLS showed that their accumulation was greater in inflorescences and leaves, with higher concentrations in autumn and spring. The activation of GLS synthesis by salinity was restricted to several cultivars and depended on the season, with no reductions compared to control plants. In this study, we discuss the appearance of a Cinnamoyl-indol-GLS derivative in some of the cultivars and seasons with higher incidence in $\mathrm{NaCl}$-treated plants.

Keywords: Cinnamoyl-indol-GLS, water relations, inflorescence yield, mineral nutrients

\section{Introduction}

The provision of plants and plant products with enhanced nutritional and medicinal qualities is becoming a great challenge (Raskin and Ripoll, 2004). Potential health-promoting compounds, which have been widely described, are glucosinolates (GLS) and their degradation products from Brassica species (Brandt et al., 2004; Moreno et al., 2006). Glucosinolates - and products of their metabolic breakdown, the isothiocyanates - found in Brassica vegetables have been described as potent modulators of xenobiotic-metabolizing enzymes that protect DNA from damage (Gerhauser, 2013). Therefore, high intake of cruciferous vegetables is associated with a reduced risk of cancer, particularly lung and gastrointestinal (Lund, 2003), cardiovascular diseases (Angelino and Jeffery, 2014), and, to a lesser extent, prostate cancer (Kristal and Lampe, 2002). Glucosinolates are chemically defined compounds, all GLS characterized, and share a similar basic structure consisting of a B-D-thioglucose group. Glucosinolates are converted into isothiocyanates or indoles by the activity of myrosinase (Martinez-Ballesta and Carvajal, 2015).

Salinity is one of the most prevalent limiting factors for crop production $(\mathrm{Zhu}, 2001)$. Previous studies focused on the adaptation mechanisms of broccoli (Brassica oleracea L. var. italica) to salinity (Zaghdoud et al., 2012; 2016). In addition, changes in the GLS concentration in response to salinity have been related to their participation in signaling mechanisms (LópezBerenguer et al., 2009). Hence, quantitative and qualitative changes in the GLS profile occur in response to environmental changes, although their specific func- tions are still unknown. This is of particular importance in the case of broccoli cultivars, where different GLS are involved in plant defense against abiotic stress (Martinez-Ballesta et al., 2013). The GLS response to salinity may vary according to the experimental conditions, such as temperatures (Schonhof et al., 2007), the type of glucosinolate, and plant genotype (DominguezPerles et al., 2011; López-Berenguer et al., 2009).

The aim of this work was to determine the GLS profile of seven broccoli cultivars grown under the current environmental conditions of the Mediterranean semiarid zones of production (Murcia, southeast Spain), during the autumn, winter, and spring seasons. Through the analysis of all organs of the plants (root, leaves, and inflorescence), the effect of irrigation with saline water was determined in terms of suitability of using this abiotic stress to stimulate GLS synthesis. Moreover, the detection of novels molecular species, feruloyl-indol-glucosinolates (F-GLS), in some of the cultivar-treatment combinations is reported.

\section{Materials and Methods}

\section{Plant material and growth conditions}

Seven commercial broccoli cultivars were used: Parthenon, Naxos, Heraklion, Triton, Marathon, Gea, and Mykonos. All the seedlings were obtained from a commercial nursery for horticultural plants in Murcia (Spain). Three experiments were conducted during different seasons, in the field on an experimental farm in Murcia (Spain), under a semiarid Mediterranean climate (geographic coordinates: $37^{\circ} 47^{\prime} 52.7^{\prime \prime} \mathrm{N}$, $0^{\circ} 52^{\prime} 00.7^{\prime \prime} \mathrm{W}, 15 \mathrm{~m}$ asl). The first crop was planted in October and harvested in December, while the second 
crop was planted in January and harvested in March, and the third crop was planted in April and harvested in June.

The temperature and relative humidity were recorded every $10 \mathrm{~min}$ using dataloggers (Table 1). We planted 360 plants, 180 per treatment (control and salinity), in a $300 \mathrm{~m}^{2}$ plot, with a randomized block design. We planted 360 plants, 180 per treatment (control and salinity), in a $300-\mathrm{m}^{2}$ plot, with a randomized block design. All plants were drip-irrigated with fertirrigation with $\mathrm{CaNO}_{3}\left(3.7 \mathrm{~g} \mathrm{~m}^{2}\right.$ in autumn and winter and 7.5 $\mathrm{g} \mathrm{m}^{2}$ in spring) and $\mathrm{K}_{2} \mathrm{NO}_{3}\left(2.2 \mathrm{~g} \mathrm{~m}^{2}\right.$ in autumn and winter and $5.2 \mathrm{~g} \mathrm{~m}^{2}$ in spring). In the salinity treatment, $80 \mathrm{mM} \mathrm{NaCl}$ was added to the nutrient solution $\left(7.3 \mathrm{dS} \mathrm{m}^{-1}\right)$. The plants were harvested when inflorescences reached commercial size. The cultivars Naxos, Heraklion, and Mykonos were harvested 79 days after transplanting the seedlings, while Parthenon, Triton, Marathon and Gea after 86 days of transplanting. The inflorescences were separated from the rest of the plant and weighed. We analyzed the GLS of the inflorescences, leaves, and roots.

\section{Intact glucosinolates analysis}

Freeze-dried fine powders (100 mg) of inflorescences, leaves, and roots were extracted in $1 \mathrm{~mL}$ of 70 $\%$ methanol at $70{ }^{\circ} \mathrm{C}$ during $30 \mathrm{~min}$, vortexing every 5 min (Dominguez-Perles et al., 2011). Afterwards, the samples were placed in ice bath to stop the reaction and then centrifuged for $15 \mathrm{~min}$ at $13000 \mathrm{rpm}$, at $4{ }^{\circ} \mathrm{C}$. The supernatants were collected and the methanol was removed using a rotary evaporator. Each dried residue was re-dissolved in ultrapure Milli-Q water to the initial volume of the supernatant and filtered through a $0.2-\mu \mathrm{m}$ polyethersulfone membrane filter.

The HPLC-DAD analyses were carried out in a binary capillary pump equipped with an autosampler, a degasser, a sample cooler, and a photodiode array detector. The compounds were separated in a Luna C18 column $(25 \mathrm{~cm} \times 0.46 \mathrm{~cm}, 5 \mu \mathrm{m}$ particle size $)$. The mobile phase was a mixture of water/trifluoroacetic acid (99.9:0.1, v/v) (A) and acetonitrile/trifluoroacetic

Table 1 - Average values of environmental conditions in each month during experiments.

\begin{tabular}{lcccc}
\hline Month & Sun & Rainfall & Temperature & Radiation \\
\hline & $\mathrm{h}$ & $\mathrm{L} \mathrm{m}^{-2}$ & ${ }^{\circ} \mathrm{C}$ & $\mathrm{W} \mathrm{m}^{-2}$ \\
Sept & 265 & 7.8 & 19.94 & 203.54 \\
Oct & 271 & 31.8 & 19.06 & 161.56 \\
Nov & 231 & 28.3 & 14.81 & 129.15 \\
Dec & 220 & 6 & 12.89 & 98.83 \\
Jan & 214 & 8.6 & 12.62 & 109.83 \\
Feb & 235 & 5.4 & 13.03 & 142.06 \\
Mar & 296 & 23 & 13.57 & 221.07 \\
Apr & 321 & 22.3 & 15.85 & 257.62 \\
May & 358 & 3.4 & 18.4 & 305.69 \\
\hline June & 369 & 0 & 22.75 & 346.88 \\
\hline
\end{tabular}

acid (99.9:0.1, v/v) (B). The flow rate was $1 \mathrm{~mL} \mathrm{~min}^{-1}$ in a linear gradient, starting with $1 \% \mathrm{~B}$ for 5 min and reaching $17 \% \mathrm{~B}$ at $15 \mathrm{~min}$ (maintained for $2 \mathrm{~min}$ ), $25 \%$ $\mathrm{B}$ at $22 \mathrm{~min}, 35 \% \mathrm{~B}$ at $30 \mathrm{~min}, 50 \% \mathrm{~B}$ at $35 \mathrm{~min}$, and $99 \% \mathrm{~B}$ at $40 \mathrm{~min}$. The monitored compounds eluted off the column in $35 \mathrm{~min}$. The identification of the glucosinolates was carried out according to their UV-Vis spectra, retention times and comparison with authentic standards. Compounds were quantified using sinigrin (SIN) and glucobrassicin (GBS) as external standards of aliphatic and indole GLS, respectively. The concentrations were expressed as $\mathrm{mg} \mathrm{g}^{-1}$ of DW.

\section{Statistical analysis}

The data were analyzed using the software SPSS Release 18 for Windows. Duncan's test at $p \leq 0.05$ was chosen to determine the significance of differences between groups.

\section{Results}

Regarding the results of inflorescence yield (Figures $1 \mathrm{~A}, \mathrm{~B}$ and $\mathrm{C}$ ), during the autumn season, the values were higher for cultivar Gea under control conditions. When salinity was applied, there was a significant yield increase in Triton and Marathon and a significant decrease in Gea. In the rest of the cultivars (Parthenon, Naxos, Heraklion, and Mykonos), no differences in yield between control and $\mathrm{NaCl}$-treated plants were observed. During the winter season, there were no significant differences among the seven cultivars studied and Triton, Marathon, Gea, and Mykonos showed values slightly lower than in autumn. Salinity did not significantly affect any of the cultivars. In the spring season, Parthenon and Mykonos had higher yields than in the rest of the seasons while the other cultivars showed yields similar to those in winter. Salinity affected Parthenon negatively and Triton positively, but it did not produce significant differences in Naxos, Heraklion, Marathon, Gea, or Mykonos. No variation was found in $\%$ water between cultivars, seasons and treatments (ranged from 88-91\%, data not shown).

The analysis of GLS in inflorescences in the autumn season (Table 2) showed that the glucoraphanin (GRA) and glucobrassicin (GBS) concentrations were higher than in the rest of the GLS (4-hydroxyglucobrassicin (HGB), metoxiglucobrassicin (MGB), neoglucobrassicin (NGB). In addition, in control conditions, the levels of GLS were only significantly higher in Gea (Figure 2). Salinity increased significantly the total GLS concentrations in cultivars Triton and Marathon, mainly due to increases in GRA, while the GBS concentration rose in Parthenon, Heraklion, and Triton (Table 2). No significant differences were found for the rest of the GLS.

In leaves, also, the most abundant GLS were GRA and GBS (Table 2). In this organ, salinity provoked an increase in total GLS in all cultivars and was signifi- 


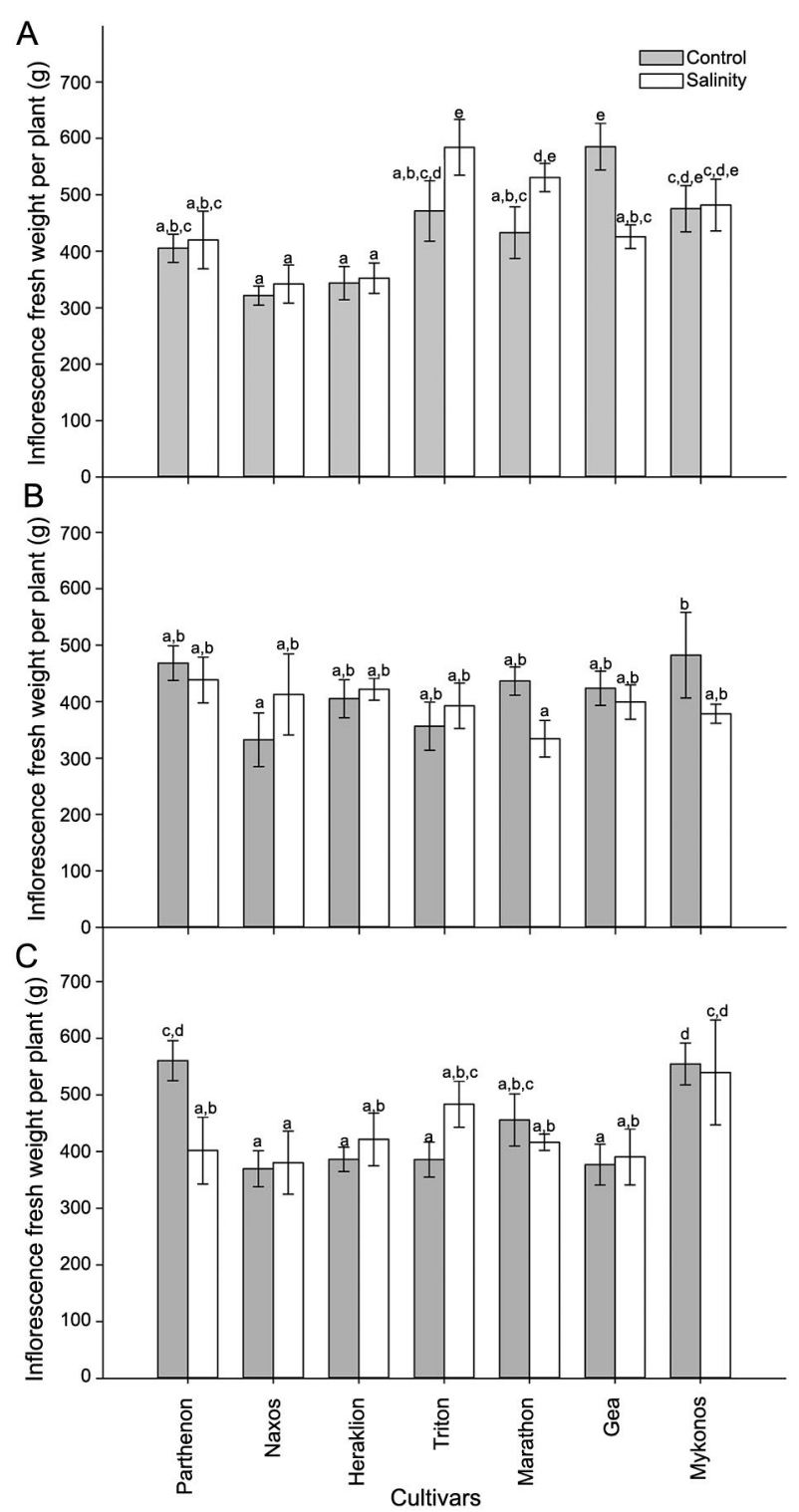

Figure 1 - Inflorescence yield of different broccoli cultivars grown in control and saline conditions, in the field, during the (A) autumn, (B) winter, and (C) spring seasons. Bars with different letters show significant differences according to the Duncan's test at $p<0.05$. Values are means \pm SE $(n=5)$.

cant in Triton, Marathon, and Mykonos (Figure 2). The increases were due to GBS in Triton, Marathon, and Gea, to MGB in Naxos and Marathon, and to NGB in Mykonos.

In roots of plants grown in autumn, there was an increase in total GLS in Heraklion, Triton, and Marathon, in relation to winter and spring (Figure 2). In these cases, different GLS appeared, such as gluconapin (GNA) and gluconasturtin (PE) (Table 2). The higher total values observed were due to a higher concentration of GRA in Heraklion, of GNA in Heraklion and Gea, of GBS in Heraklion, Triton, and Marathon, of MGB in Heraklion and Triton, and of NGB in all the cultivars.

When the crop grew in the winter season, the general levels of GLS in inflorescences were lower than in autumn (Figure 2), while in leaves and roots, the levels were similar for both seasons. In this case, the levels of total GLS in inflorescences under control conditions were higher in Naxos and lower for Gea. The salinity treatment did not produce an apparent change in inflorescences and leaves in any of the cultivars; however, in roots, there was an increase in all the cultivars except for Parthenon. The increases in total GLS in roots were due to higher levels of GRA, PE, GBS, MGB, and NGB (Table 3).

In the spring season, the total GLS concentration was much higher than in the rest of the seasons, nearly double in most cultivars (Figure 2). In inflorescences, the concentration was higher under saline conditions in Heraklion, Gea, and Mykonos and was lower in Naxos, with no significant differences in the rest of the cultivars. The increases were due to GRA in Heraklion, to GBS in Heraklion and Gea, and to NGB in Gea and Mykonos (Table 4).

In leaves, an increase in total GLS caused by salinity was observed in Parthenon, Heraklion, and Gea (Figure 2). The increases were due to GRA in Heraklion and Gea, to GBS in Parthenon and Gea, to MGB in Gea, and to NGB in Parthenon, Heraklion, and Gea (Table 4).

In roots, the total GLS concentration was increased significantly by salinity only in Parthenon (Figure 2), mainly due to increases in GBS and NGB.

The detection of a cinnamoyl-indol-glucosinolate is shown in Table 5. In leaves and inflorescences of plants grown during the autumn season, it only appeared - at low concentrations - in Parthenon Triton, and Marathon when salinity was applied and with no significant differences between cultivars. However, this compound was not observed in roots of any of the cultivars or treatments.

During the winter season, the cinnamoyl-indolGLS was not detected in leaves or inflorescences of any of the cultivars. However, this complex compound appeared in roots of Parthenon, Marathon, and Gea. In this season, the concentrations were also very low and no significant differences between cultivars were observed.

In the spring samples, the presence of the cinnamoyl-indol-GLS was more intense in the roots, leaves and inflorescences of Parthenon, Triton, and Marathon, in untreated (control) and NaCl-treated plants. For Mykonos, it was only detected in NaCl-treated plants. In leaves, the occurrence according to the cultivar and treatment was similar to that in inflorescences. However, in this organ, the concentrations in NaCl-treated plants were always higher than in the control. In roots, the cinnamoyl-indol-GLS was observed in all cultivars and in both treatments (control and $\mathrm{NaCl}$ ), but the concentration in $\mathrm{NaCl}$-treated plants was higher than in the control. 


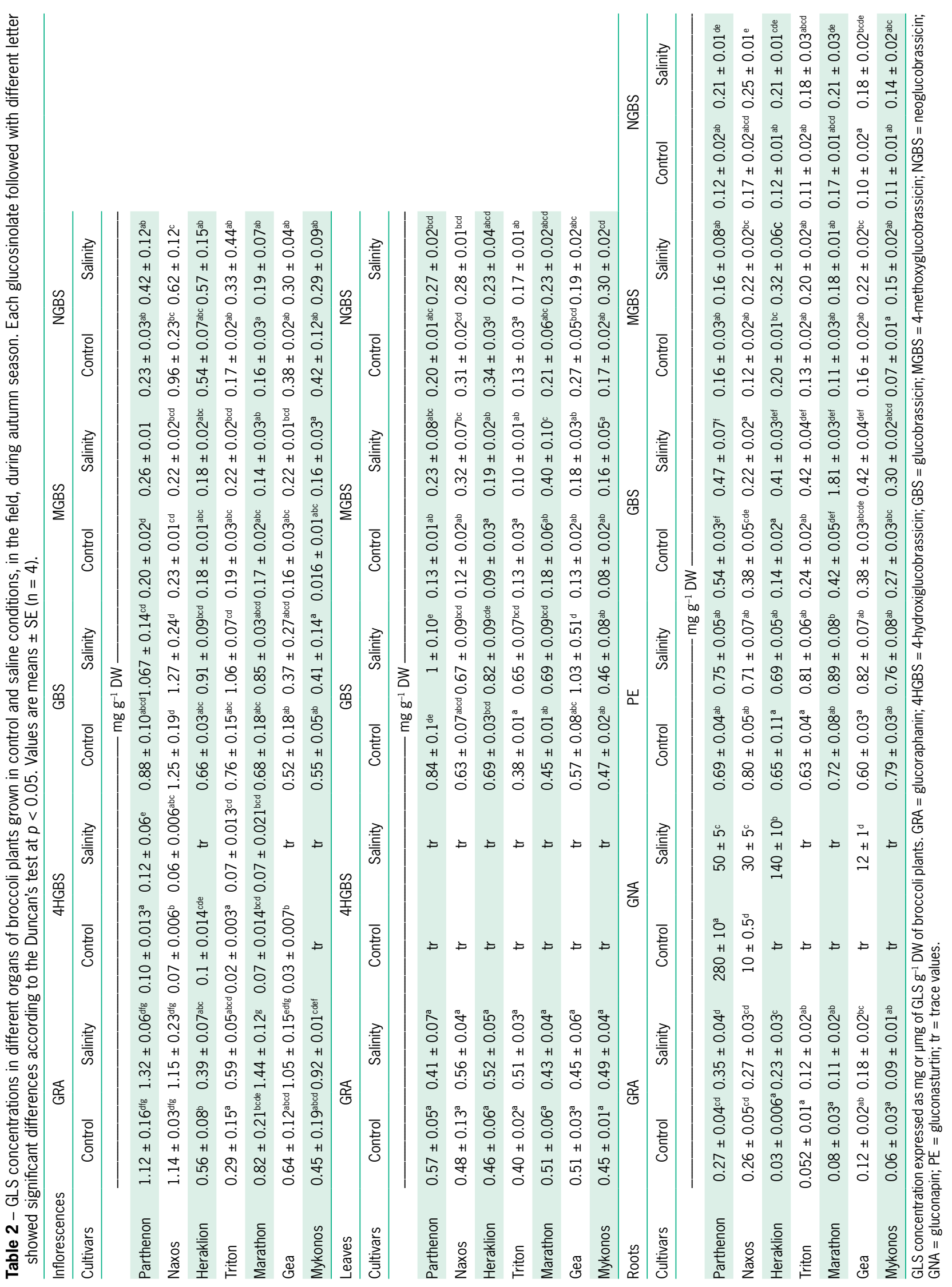




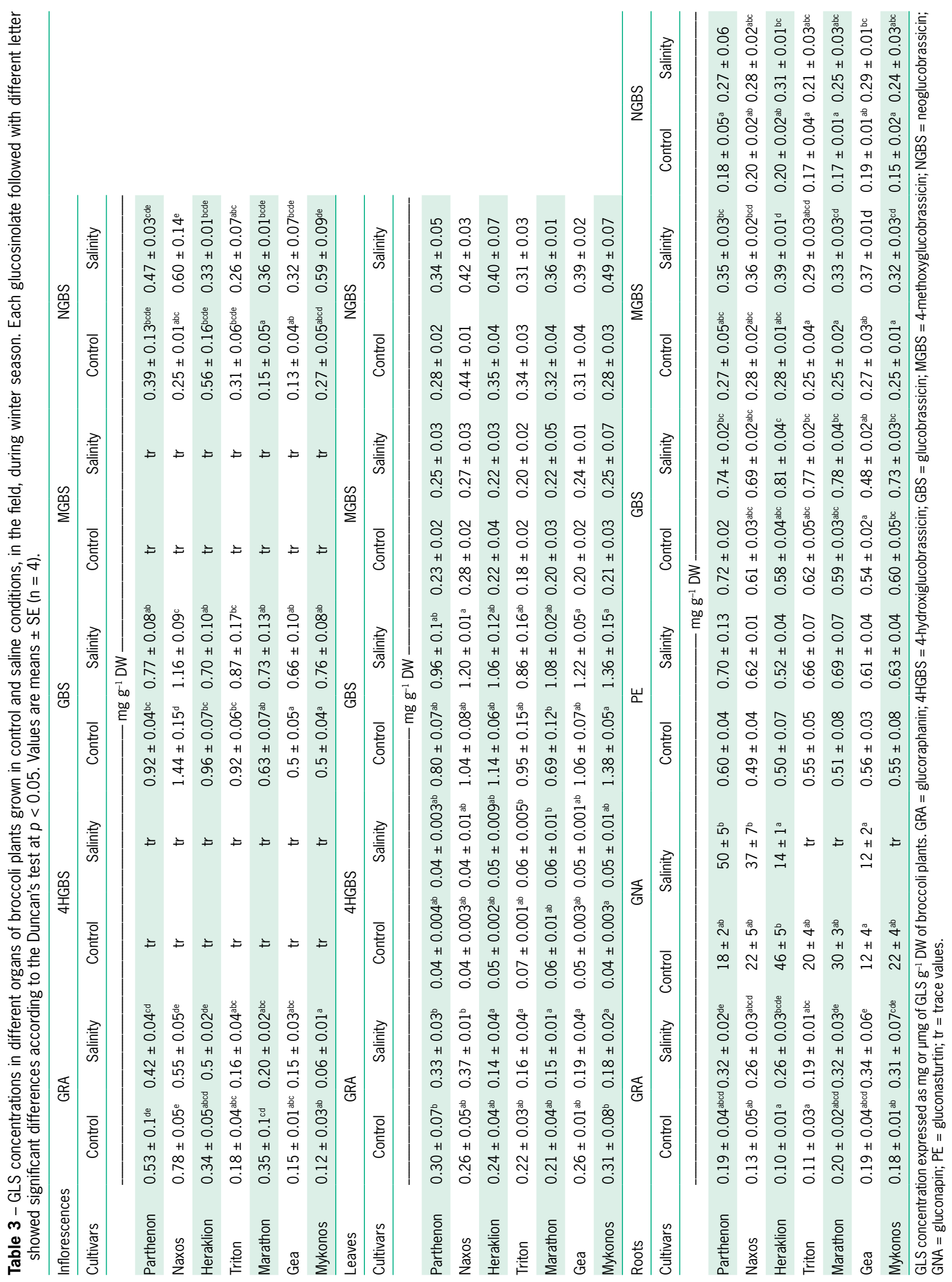




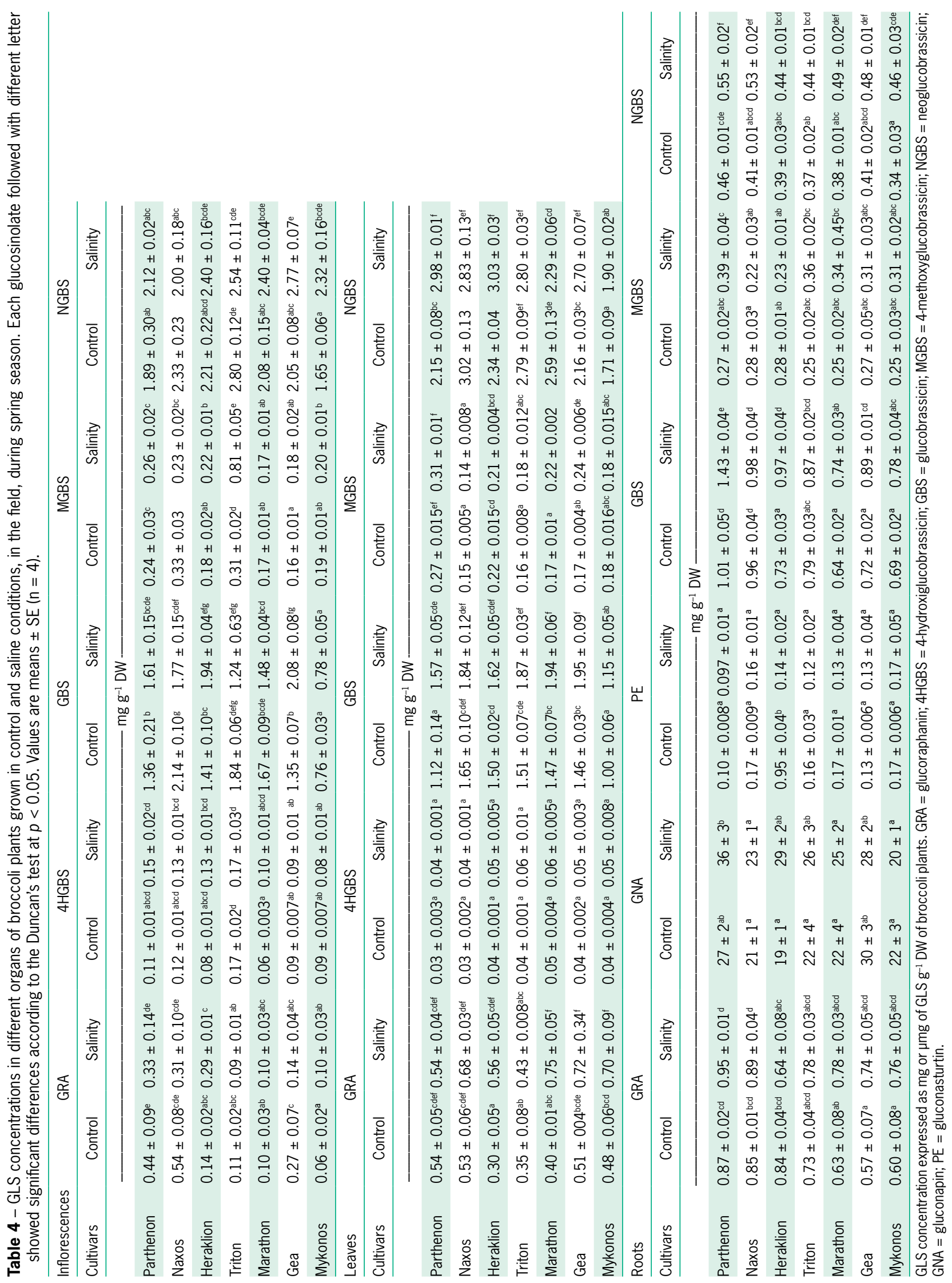




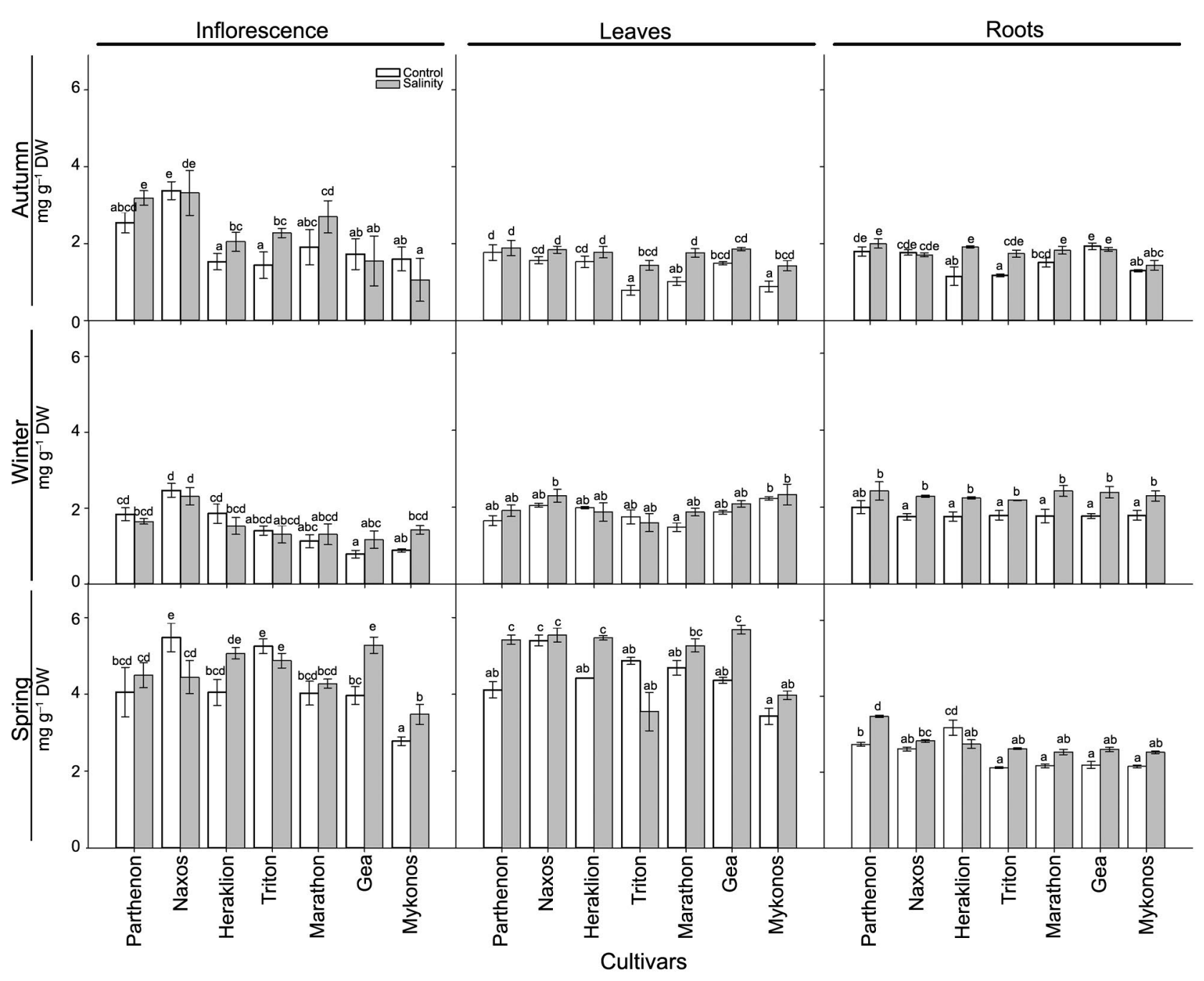

Figure 2 - Total GLS concentrations in different organs of broccoli plants grown in control and saline conditions, in the field, during the autumn, winter, and spring seasons. For each glucosinolate, different letters show significant differences according to the Duncan's test at $p<0.05$. Values are means \pm SE $(n=4)$.

\section{Discussion}

Growth reductions in broccoli has been reported to depend on the duration of stress application. Thus, a two-phase growth decrease in response to salinity has been recorded (López-Berenguer et al., 2006). The first phase of growth reduction was reported to be due to water stress, while the second phase was derived from internal damage due to salt $\left(\mathrm{Na}^{+}\right)$accumulation. Lower reduction of growth during the second phase was reported to be related to vacuolar compartmentalization of $\mathrm{Na}^{+}$and $\mathrm{Cl}^{-}$(Munns, 1993), in which the regulation of aquaporin functionality is key (López-Berenguer et al., 2006). In our work, the fact that there were only significant reductions in inflorescence yield with salinity in two cultivars and in specific seasons indicates that salinity was not the dominant stress at this salinity level (80
$\mathrm{mM}$ ) in field conditions. Recently, irrigation with saline water for only part of the crop cycle (until the appearance of the broccoli head or from the appearance of the broccoli head) or during the entire autumn growing season decreased the total broccoli yield by $20 \%$ and $24 \%$, respectively, compared to the control (Gioia et al., 2018). This observation is in line with our findings in previous experiments with hydroponic culture (Dominguez-Perles et al., 2011). However, in the present field experiment, the application of $80 \mathrm{mM} \mathrm{NaCl}$ through soil irrigation only reduced significantly the inflorescence weight in cultivar Gea in autumn (by $27 \%$ ) and in Parthenon in spring (by $28 \%$ ). For the rest of the cultivars, inflorescence yield was not altered significantly during any of the seasons, indicating their high tolerance of salinity together with the buffer effect of the soil. In this regard, other studies revealed salt-induced permanent modifica- 
Table 5 - Cinnamoyl-indol-GLs in different organs of broccoli plants grown under control and saline stress in the field during the autumn, winter, and spring seasons. Different letters in a column and treatment show significant differences according to the Duncan's test at $p<0.05$. Values are means $\pm S E(n=4)$.

\begin{tabular}{|c|c|c|c|c|c|c|c|}
\hline \multirow{3}{*}{ Autumn } & \multirow{3}{*}{ Cultivars } & \multicolumn{6}{|c|}{ Cinnamoyl-indol-GLS (mg g-1 DW) } \\
\hline & & \multicolumn{2}{|c|}{ Inflorescence } & \multicolumn{2}{|c|}{ Leaves } & \multicolumn{2}{|c|}{ Roots } \\
\hline & & Control & Salinity & Control & Salinity & Control & Salinity \\
\hline & Parthenon & tr & $0.006 \pm 0.001$ & $\operatorname{tr}$ & $0.010 \pm 0.002$ & $\operatorname{tr}$ & $\operatorname{tr}$ \\
\hline & Naxos & $\operatorname{tr}$ & $\operatorname{tr}$ & $\operatorname{tr}$ & $\operatorname{tr}$ & tr & $\operatorname{tr}$ \\
\hline & Heraklion & $\operatorname{tr}$ & $\operatorname{tr}$ & $\operatorname{tr}$ & $\operatorname{tr}$ & $\operatorname{tr}$ & $\operatorname{tr}$ \\
\hline & Triton & $\operatorname{tr}$ & $0.010 \pm 0.001$ & $\operatorname{tr}$ & $0.010 \pm 0.001$ & $\operatorname{tr}$ & $\operatorname{tr}$ \\
\hline & Marathon & $\operatorname{tr}$ & $0.010 \pm 0.001$ & $\operatorname{tr}$ & $0.030 \pm 0.001$ & $\operatorname{tr}$ & $\operatorname{tr}$ \\
\hline & Gea & tr & $\operatorname{tr}$ & $\operatorname{tr}$ & $\operatorname{tr}$ & $\operatorname{tr}$ & $\operatorname{tr}$ \\
\hline & Mykonos & tr & $\operatorname{tr}$ & tr & tr & tr & $\operatorname{tr}$ \\
\hline \multicolumn{8}{|l|}{ Winter } \\
\hline & Parthenon & $\operatorname{tr}$ & $\operatorname{tr}$ & $\operatorname{tr}$ & $\operatorname{tr}$ & $0.020 \pm 0.007$ & $0.030 \pm 0.005$ \\
\hline & Naxos & tr & tr & $\operatorname{tr}$ & tr & $\operatorname{tr}$ & $\operatorname{tr}$ \\
\hline & Heraklion & tr & tr & tr & tr & tr & tr \\
\hline & Triton & tr & tr & tr & tr & tr & $\operatorname{tr}$ \\
\hline & Marathon & $\operatorname{tr}$ & tr & $\operatorname{tr}$ & $\operatorname{tr}$ & $0.010 \pm 0.002$ & $0.020 \pm 0.007$ \\
\hline & Gea & tr & tr & $\operatorname{tr}$ & tr & $0.005 \pm 0.001$ & $0.006 \pm 0.002$ \\
\hline & Mykonos & tr & tr & $\operatorname{tr}$ & tr & tr & tr \\
\hline \multicolumn{8}{|l|}{ Spring } \\
\hline & Parthenon & $0.010 \pm 0.001^{a}$ & $0.020 \pm 0.001^{\mathrm{ab}}$ & $0.020 \pm 0.001^{b}$ & $0.030 \pm 0.001^{b c}$ & $0.020 \pm 0.003^{\mathrm{ab}}$ & $0.040 \pm 0.001^{c}$ \\
\hline & Naxos & tr & $0.010 \pm 0.001^{a}$ & $\operatorname{tr}$ & tr & $0.010 \pm 0.001^{a}$ & $0.020 \pm 0.003^{a b}$ \\
\hline & Heraklion & tr & $\operatorname{tr}$ & $\operatorname{tr}$ & tr & $0.010 \pm 0.001^{a}$ & $0.020 \pm 0.001^{b}$ \\
\hline & Triton & $0.020 \pm 0.001^{a b}$ & $0.040 \pm 0.001^{b}$ & $0.010 \pm 0.001^{a}$ & $0.020 \pm 0.001^{b}$ & $0.010 \pm 0.001^{a}$ & $0.030 \pm 0.001^{b c}$ \\
\hline & Marathon & $0.030 \pm 0.001^{b}$ & $0.040 \pm 0.002^{b}$ & $0.010 \pm 0.001^{a}$ & $0.040 \pm 0.001^{c}$ & $0.020 \pm 0.02^{\mathrm{ab}}$ & $0.040 \pm 0.002^{c}$ \\
\hline & Gea & $\operatorname{tr}$ & $\operatorname{tr}$ & $\operatorname{tr}$ & $\operatorname{tr}$ & $0.010 \pm 0.001^{a}$ & $0.010 \pm 0.001^{a}$ \\
\hline & Mykonos & tr & $0.010 \pm 0.001^{a}$ & $\operatorname{tr}$ & $0.020 \pm 0.002^{b}$ & $0.010 \pm 0.001^{a}$ & $0.020 \pm 0.001^{a b}$ \\
\hline
\end{tabular}

Cinnamoyl-indol-GLS concentrations are expressed as: $\mathrm{mg} \mathrm{g}^{-1} \mathrm{DW} ; \mathrm{tr}=$ trace values.

tions of soil physical-chemical properties, affecting yield of broccoli cultivar Marathon grown during the winter, in agreement with our results (De Pascale et al., 2005).

In addition, the effect of the season was dependent on the cultivar: Triton, Marathon, and Gea had higher inflorescence weights during the autumn, whereas Parthenon and Mykonos had higher yields in spring. For all the other cultivars and seasons, the weight was around 400 to $450 \mathrm{~g}$ per inflorescence, with no significant differences. It has been reported that when multiple abiotic stresses were applied to different Brassica oleracea L. crop types, no relevant differences were found among them, which is promising for the development of more environmentally robust lines (Beacham et al., 2017). Therefore, if we consider the different temperatures and day lengths of the seasons as additional stresses to salinity, this can explain the differing responses of the cultivars studied.

The GLS determined here (GRA, GBS, HGB, MGB, NGB) had a profile different from that of broccoli cultivars studied previously (in which glucoiberin was present), which were grown under different (crop chamber and greenhouse) conditions (DominguezPerles et al., 2011; López-Berenguer et al., 2009), suggesting that field conditions orientated the secondary metabolism through different pathways. Still, other ex- periments carried out in field conditions showed different profile in similar cultivars as Marathon (Vallejo et al., 2003) pointing that GLs should be investigated for each individual condition. The results in previous work showed a marked increase in GLS abundance in young leaves with salinity, higher with the $40 \mathrm{mM} \mathrm{NaCl}$ treatment than with $80 \mathrm{mM} \mathrm{NaCl}$; however, in inflorescences, GLS abundance increased regardless of the $\mathrm{NaCl}$ concentration applied (López-Berenguer et al., 2009). Moreover, the three cultivars studied previously and grown in perlite under greenhouse conditions - 'Nubia', 'Naxos', and 'Parthenon' - showed an increase in GLS due to $\mathrm{NaCl}$ application (40 $\mathrm{mM} \mathrm{NaCl}$ ), which was apparently co-influenced by the growth temperature (Dominguez-Perles et al., 2011). Furthermore, under the field conditions of our experiment the increase in GLS levels due to salinity depended on the season and cultivar, influenced more by the temperature increase than by salinity for most cultivars. Other authors reported that the spring-summer climatic conditions increased directly the concentration of GLS (Aires et al., 2011), leading to higher antioxidant activity in broccoli inflorescences and kale leaves. In our experiment, additional enhancement by salinity and higher temperatures was only observed in Heraklion, Gea, and Mykonos. 
In our cultivars, the indole GLS were influenced by salinity more than the aliphatic GLS. In addition, inflorescences and leaves showed higher GLS concentrations than roots in autumn and spring, and similar values (or lower for cultivars Triton, Marathon, and Gea) in winter. In this sense, additional stress factors, such as temperature that influenced GLS production in our cultivars, as the concentrations in inflorescences and leaves in spring were double than those in autumn and 3-fold greater than in winter. However, root concentrations remained similar in all seasons. It has been proposed that, since the GLS profile of root tissues differs from that in leaves and inflorescences, their associated isothiocyanates (GLS hydrolysis products) would also be different (Lee et al., 2017). Furthermore, the reported low nitrile formation capacity in root tissues was related to the low epithiospecifier protein gene transcription, which made the roots of broccoli a good source of isothiocyanates (Zhang et al., 2006).

The activation of GLS synthesis has been related to the recent description of WD40 domain proteins, and activator- and repressor-type transcription factors of the R2R3-type myeloblastosis (MYB), R3-type MYB, and basic helix-loop-helix (bHLH) families have been identified that regulate plant secondary metabolism and associated specialized cell development across diverse plant species, suggesting an ancient transcriptional component of gene regulatory networks in plants (Chezem and Clay, 2016). These authors pointed out that the biosynthetic pathways of phenylpropanoids and GLS are associated to transcriptional mechanisms that regulate the production of both. The direct regulatory network controlling GLS synthesis in Arabidopsis involves activator-type MYBs from subgroup 12 (Zhong et al., 2007), which are activated by biotic (Ahuja et al., 2010) and abiotic stress (Martínez-Ballesta et al., 2013).

One interesting point of our results is the appearance of a cinnamoyl-indol-glucosinolate in broccoli inflorescences. This type of derivatives has been described in broccoli (Survay et al., 2010) and the occurrence of this type of compounds was also confirmed by the HPLCDAD-ESI-MSn analysis of broccoli florets and in Arabidopsis (Survay et al., 2010; Lee et al., 2012), as well as in representatives of the Cardamineae tribe (Olsen et al., 2016). In our experiment, this derivative was induced in some of the cultivars, but only under saline conditions in autumn and winter. The physiological relevance of these type of compounds remains unclear; however, they can act as signal molecules involved in the machinery of plant defense (Chezem and Clay, 2016). This cinnamoyl-indol-GLS could be a signal molecule participating in a negative feedback to prevent over-production of GLS under stress (Heinze et al., 2015), a mode of action that requires further investigation.

It can be concluded that broccoli grown in field conditions is tolerant of moderate salinity $(80 \mathrm{mM} \mathrm{NaCl})$ in autumn, winter, and spring. In fact, the inflorescence weight was reduced significantly by $\mathrm{NaCl}$ exposure only for cultivars Gea, in autumn, and Parthenon, in spring. In addition, the total GLS concentration was increased by salinity in cultivars Parthenon, Heraklion, Triton, and Marathon, in autumn, and in Heraklion and Gea, in spring, representing a good technique for stimulation of GLS synthesis. The spring conditions led to much higher GLS accumulation, with an additional effect of salinity only in cultivars Heraklion, Gea, and Mykonos. Interestingly, the appearance of cinnamoyl-indol-GLS under stress-induced conditions and acting as signal molecule deserves further investigation.

\section{Acknowledgements}

This work was funded by the Spanish Ministerio de Ciencia, Innovación y Universidades (AGL201680247-C2-1-R and RTC-2015-3536-2). The authors thank Dr. David Walker for the revision of the written English in the manuscript.

\section{Authors' Contributions}

Conceptualization: Carvajal, M. Data acquisition: Rios, J.J.; Agudelo, A.; Data analysis: Rios, J.J.; Agudelo, A.; Moreno, D. Design of methodology: Moreno, D.; Carvajal, M. Writing and editing: Rios, J.J.; Agudelo, A.; Moreno, D.; Carvajal, M. Rios J.J. and Agudelo A. contributed equally

\section{References}

Ahuja, I.; Rohloff, J.; Bones, A.M. 2010. Defense mechanisms of Brassicaceae: implications for plant-insect interactions and potential for integrated pest management. Agronomy for Sustainable Development 30: 311-348.

Aires, A.; Rosa, E.; Carvalho, R. 2011. Effect of nitrogen and sulfur fertilization on glucosinolates in the leaves and roots of broccoli sprouts (Brassica oleracea var. italica). Journal of Science and Food Chemistry 86: 1512-1516.

Angelino, D.; Jeffery, E. 2014. Glucosinolate hydrolysis and bioavailability of resulting isothiocyanates: focus on glucoraphanin. Journal of Functional Food 7: 67-76.

Beacham, A.M.; Hand, P.; Pink, D.A.C.; Monagham, J.M. 2017. Analysis of Brassica oleracea early stage abiotic stress responses revels tolerance in multiple crop types and for multiple sources of stress. Journal of Science and Food Chemistry 97: 5271-5277.

Brandt, K.; Christensen, L.P.; Hansen-Møller, J.; Hansen, S.L.; Haraldsdottir, J.; Jespersen, L.; Purup, S.; Kharazmi, A.; Barkholt, V.; Frøkiær, H.; Kobæk-Larsen, M. 2004. Health promoting compounds in vegetables and fruits: a systematic approach for identifying plant components with impact on human health. Trends in Food Science and Technology 15: 384-393.

Chezem, W.R.; Clay, N.K. 2016. Regulation of plant secondary metabolism and associated specialized cell development by MYBs and bHLHs. Phytochemistry 131: 26-43.

De Pascale, S.; Maggio, A.; Barbieri, G. 2005. Soil salinization affects growth, yield and mineral composition of cauliflower and broccoli. European Journal of Agronomy 23: 254-264. 
Di Gioia, F.; Rosskopf, E.N.; Leonardi, C.; Guiffrida, F. 2018. Effects of application timing of saline irrigation water on broccoli production and quality. Agricultural Water Management 203: 97-104.

Dominguez-Perles, R.; Martinez-Ballesta M.C.; Carvajal, M.; Garcia-Viguera, C.; Moreno, D.A. 2011. Novel varieties of broccoli for optimal bioactive components under salinity stress. Journal of Agricultural and Food Chemistry 91: 16381647.

Gerhauser, C. 2013. Epigenetic impact of dietary isothiocyanates in cancer chemoprevention. Current Opinion in Clinical Nutrition and Metabolic Care 16: 405-410.

Heinze, M.; Brandt, W.; Marillonnet, S.; Roos, W. 2015. "Self" and "non-self" in the control of phytoalexin biosynthesis: plant phospholipases A2 with alkaloid-specific molecular fingerprints. The Plant Cell 27: 448-462.

Kristal, A.R.; Lampe, J.W. 2002. Brassica vegetables and prostate cancer risk: a review of the epidemiological evidence. Nutrition and Cancer 42: 1-9.

Lee, S.; Kaminaga, Y.; Cooper, B.; Pichersky, E.; Dudareva, N.; Chapple, C. 2012. Benzoylation and sinapoylation of glucosinolate R-groups in Arabidopsis. The Plant Journal 72: 411-422.

Lee, Y.S.; Ku, K.M.; Becker, T.M.; Juvik, J.A. 2017. Chemopreventive glucosinolate accumulation in various broccoli and collard tissues: microfluidic-based targeted transcriptomics for by-product valorization. PLoS One 12: e0185112.

López-Berenguer, C.; García-Viguera, C.; Carvajal, M. 2006. Are root hydraulic conductivity responses to salinity controlled by aquaporins in broccoli plants? Plant and Soil 279: 13-23.

López-Berenguer, C.; Martínez-Ballesta, M.C.; Moreno, D.A.; Carvajal, M.; García-Viguera, C. 2009. Growing hardier crops for better health: salinity tolerance and the nutritional value of broccoli. Journal of Agricultural and Food Chemistry 57: 572-578.

Lund, E. 2003. Non-nutritive bioactive constituents of plants: dietary sources and health benefits of glucosinolates. International Journal for Vitamin and Nutrition Research 73: 135-143.

Martinez-Ballesta, M.C.; Carvajal, M. 2015. Myrosinase in Brassicaceae: the most important issue for glucosinolate turnover and food quality. Phytochemistry Reviews: 16.

Martínez-Ballesta, M.C.; Moreno, D.A.; Carvajal, M. 2013. The physiological importance of glucosinolates on plant response to abiotic stress in Brassica. International Journal of Molecular Science 14: 11607-11625.

Moreno, D.A.; Pérez-Balibrea, S.; Gracía-Viguera, C. 2006. Phytochemical quality and bioactivity of edible sprouts. Natural Product Communication 1: 1037-1048.
Munns, R. 1993. Physiological processes limiting plant growth in saline soils: some dogmas and hypotheses. Plant, Cell \& Environmental 16: 15-24.

Olsen, C.E.; Huang, X.; Hansen, C.I.C.; Cipollini, D.; Ørgaard, M.; Matthes, A.; Geu-Flores, F.; Koch, M.A.; Agerbirk, N. 2016. Glucosinolate diversity within a phylogenetic framework of the tribe Cardamineae (Brassicaceae) unraveled with HPLC-MS/MS and NMR-based analytical distinction of 70 desulfoglucosinolates. PhytoChemisttry 132: 33-56.

Raskin, I.; Ripoll, C. 2004. Can an apple a day keep the doctor away? Current of Pharmacology Design 10: 3419-3429.

Schonhof, I.; Blankenburg, D.; Müller, S.; Krumbein, A. 2007. Sulfur and nitrogen supply influence growth, product appearance, and glucosinolates concentration of broccoli. Journal of Plant Nutrition and Soil Science 170: 65-72.

Survay, N.S.; Kumar, B.; Upadhyaya, C.P.; Ko, E.Y.; Lee, C.H.; Choi, J.N.; Yoon, D.Y.; Park, S.W. 2010. Characterization of a cinnamoyl derivative from broccoli (Brassica oleracea L. var. italica) florets. Fitoterapia 81: 1062-1066.

Vallejo, F.; Tomás-Barberán, F.A.; Benavente-García, A.G.; García-Viguera, C. 2003. Total and individual glucosinolate contents in inflorescences of eight broccoli cultivars grown under various climatic and fertilization conditions. Journal of Agricultural and Food Chemistry 83: 307-313.

Zaghdoud, C.; Alcaraz-López, C.; Mota-Cadenas, C.; MartínezBallesta, M.C.; Moreno, D.A.; Ferchichi, A.; Carvajal, M. 2012. Differential responses of two broccoli (Brassica oleracea L. var. Italica) cultivars to salinity and nutritional quality improvement. Scientific World Journal 291435.

Zaghdoud, C.; Carvajal, M.; Moreno, D.A.; Ferchichi, A.; Martínez-Ballesta, M.C. 2016. Health-promoting compounds of broccoli (Brassica oleracea L. var. italica) plants as affected by nitrogen fertilisation in projected future climatic change environments. Journal of Science and Food Agriculture 96: 694-702.

Zhang, Z.; Ober, J.A.; Kliebenstein, D.J. 2006. The Gene Controlling the Quantitative Trait Locus EPITHIOSPECIFIER MODIFIER1 alters glucosinolate hydrolysis and insect resistance in Arabidopsis. The Plant Cell 18: 1524-1536.

Zhong, R.; Richardson, E.A.; Ye, Z.H. 2007. The MYB46 transcription factor is a direct target of SND1 and regulates secondary wall biosynthesis in Arabidopsis. The Plant Cell 19: 2776-2792.

Zhu, J.K. 2001. Cell signaling under salt stress, water and cold stresses. Current Opinion in Plant Biology 4: 401-406. 